\section{Equivalência conceitual, de itens e semântica da versão brasileira do instrumento Dysfunctional Voiding Scoring System (DVSS) para avaliação de disfunção do trato urinário inferior em crianças}

\author{
Conceptual, item, and semantic equivalence of \\ the Brazilian version of the Dysfunctional Voiding \\ Scoring System (DVSS) instrument for evaluating \\ lower urinary tract dysfunction in children
}

Marta Rizzini 1

Teresinha Lermen Donatti 2

Denise Pimentel Bergamaschi 3

Gisela Soares Brunken 1

\author{
${ }^{1}$ Instituto de Saúde Coletiva, \\ Universidade Federal de \\ Mato Grosso, Cuiabá, Brasil. \\ 2 Hospital Universitário Júlio \\ Müller, Universidade Federal \\ de Mato Grosso, Cuiabá, \\ Brasil. \\ 3 Faculdade de Saúde \\ Pública, Universidade de São \\ Paulo, São Paulo, Brasil. \\ Correspondência \\ M. Rizzini \\ Instituto de Saúde Coletiva \\ Universidade Federal de \\ Mato Grosso. \\ Rua 03 47, Cuiabá, MT \\ 78068-844, Brasil. \\ martarizzini@hotmail.com
}

\section{Abstract}

This article investigates the conceptual, item, and semantic equivalence between the Dysfunctional Voiding Scoring System (DVSS) originally developed in English and a Portuguese-language version for use in Brazil. The instrument is used to evaluate lower urinary tract dysfunction in children. The first stage evaluated the conceptual and item equivalence, followed by two independent translations of the original instrument into Portuguese. In the second stage, 63 individuals were interviewed and items were modified according to difficulties in interpretation. In the third stage, the Portuguese instrument was back-translated into English, and the semantic equivalence was evaluated, based on referential and general (connotative) meaning. In the fourth stage, the pre-test version of the instrument was applied to 20 individuals from the target population. The Portuguese version of the instrument is presented with conceptual, item, and semantic equivalence. Nevertheless, unlike the original instrument, DVSS information collection was more adequate for the Brazilian population when performed through interviews as compared to self-applied questionnaires.

Urination Disorders; Questionnaires; Child Health
Introdução

As doenças renais, por terem repercussões crônicas, se revestem de importância clínica e econômica, sendo por isso, um problema de saúde pública. Dessa forma, todos os fatores que predispõem a uma diminuição ou perda da função renal, mesmo que indiretamente, devem ser investigados, possibilitando a prevenção e/ou a correta intervenção terapêutica. Neste contexto, a disfunção do trato urinário inferior, que indica um padrão miccional anormal gerando a perda da capacidade coordenada de armazenamento e eliminação de urina, ocupa um lugar de destaque, pois pode lesar o trato urinário superior gerando cicatrizes ou atrofias do parênquima renal 1,2 .

A disfunção do trato urinário inferior, por ser uma desordem funcional, nem sempre é evidente e o diagnóstico pode não ser feito caso não haja um grande nível de suspeição, muitas vezes só sendo detectada após lesões renais irreversíveis. A dificuldade de abordagem dos pacientes com disfunção do trato urinário inferior fomentou o desenvolvimento de instrumentos de aferição $3,4,5$, com intuito de detectar potenciais portadores desta e estabelecer critérios universalmente aceitos, que possam ser aplicados em diferentes países, culturas, idiomas e faixas etárias. Entretanto foram desenvolvidos em países de língua inglesa, muitas vezes apenas traduzidos do original para a língua portugue- 
sa/cultura brasileira pelos próprios pesquisadores ${ }^{6}$, não sendo validados, o que pode comprometer a qualidade das informações, sub ou superestimando os resultados obtidos.

Para que os instrumentos, na maior parte das vezes elaborados em países ocidentais desenvolvidos, sejam utilizados em realidades sócio-culturais tão distintas, é necessário um processo de adaptação transcultural abrangente. Herdman et al. 7 propõem a avaliação de seis tipos de equivalência: conceitual, de itens, semântica, operacional, mensuração e funcional. Modelos de adaptação transcultural com base em pesquisas mais recentes 8,9,10,11 enfatizam a importância da realização de entrevistas com o público alvo antes de proceder à retradução do texto para a língua original, permitindo uma melhor adaptação semântica e conseqüente maior compreensão do instrumento por parte da população alvo.

Um processo de adaptação, em essência, inicia-se com a avaliação da equivalência conceitual, na qual é realizado um julgamento da pertinência dos conceitos e dimensões assimilados pelo instrumento original na cultura da versão traduzida. Em seguida avalia-se a equivalência de itens que investiga se existe adequação de cada item do instrumento original em relação à capacidade de representar tais dimensões na população onde o instrumento pretende ser utilizado 11. Então é realizada a avaliação da equivalência semântica que concerne à transferência de significados entre línguas, propiciando nos respondentes das duas culturas um efeito similar 7 . A equivalência de mensuração inclui a avaliação das propriedades psicométricas do instrumento e a funcional é estabelecida após a verificação de todas as anteriores 7 .

O instrumento Dysfunctional Voiding Scoring System (DVSS), elaborado por pesquisadores da University of Toronto e The Hospital for Sick Children, no Canadá 5 , é considerado válido 6,12,13 para quantificar a severidade de comportamentos anormais de micção. Permite identificar crianças com sintomas miccionais, que podem alterar a função renal, e monitorar respostas a diversos tipos de tratamentos. A escala original é proposta para ser lida (com itens elaborados na primeira pessoa do singular) e preenchida por crianças com o auxílio dos pais e a presença de enfermeira no caso de existir alguma dúvida.

A versão original do DVSS é constituída de dez itens para avaliar a presença de disfunção do trato urinário inferior, com respostas segundo escala Likert sendo atribuídos escores de 0 a 3 de acordo com a existência do sintoma (almost never $=0$; less than half the time $=1 ;$ about half the time $=2$; almost every time $=3$ ). Os dez itens estão divididos em duas dimensões, a saber: sintomas urinários/gastrointestinais - 9 itens; e fatores ambientais (problemas social e familiar) - 1 item, sendo esse último, apesar de desmembrado em subitens, pontuado como sim (3 pontos) quando qualquer subitem é confirmado. O resultado do teste é a somatória dos valores atribuídos aos itens $($ mínimo $=0 ;$ máximo $=30)$. Curvas ROC para os sexos feminino e masculino foram utilizadas para definir os pontos de corte, sendo o escore maior que 6 pontos para meninas (sensibilidade $92,8 \%$, especificidade $87,1 \%$ ) e maior que 9 para meninos (sensibilidade $81 \%$, especificidade $91,3 \%$ ), indicadores da possibilidade de existência de disfunção do trato urinário inferior.

A aprovação para tradução e uso do instrumento foi autorizada pelo autor principal (Walid Farhat) em 26 de setembro de 2006.

Mesmo considerando o DVSS um instrumento válido e confiável, deve-se considerar a possibilidade de que a forma com que os constructos relacionados aos sintomas miccionais são abordados na cultura de origem pode diferir tanto em termos de suas definições, como nos comportamentos a eles relacionados na cultura alvo onde se pretende aplicá-los. Sendo assim, a utilização do DVSS em nosso meio, ainda que desejável, deve ser precedida de um processo formal de avaliação de sua equivalência transcultural, de forma a fornecer evidências sobre a manutenção de suas propriedades quando aplicado em diferente contexto sócio-cultural.

O objetivo do artigo é apresentar os resultados da equivalência conceitual, de itens e semântica entre o DVSS original em inglês, e uma versão em português para uso em estudos epidemiológicos empenhados em avaliar a disfunção do trato urinário inferior em crianças.

\section{Métodos}

O presente estudo foi desenvolvido em quatro etapas (Figura 1): avaliação das equivalências conceitual e de itens; aplicação na população alvo; retradução para o idioma original e avaliação da equivalência semântica e, por último; a avaliação final da versão pré-teste do instrumento e tradução do instrumento, descritas a seguir.

\section{Etapa 1: avaliação da equivalência conceitual e de itens}

Na apreciação da equivalência conceitual exploraram-se conceitos relacionados à disfunção do trato urinário inferior e às dimensões que abrangem o instrumento original (sintomas urinários/ gastrointestinais e fatores ambientais) com intuito de verificar se estas dimensões eram pertinen- 
tes e relevantes em nosso meio em relação à definição e interpretação de sintomas em crianças com disfunção do trato urinário inferior. Neste processo, avaliou-se a pertinência dos itens do instrumento original quanto a sua capacidade de captar as dimensões da disfunção do trato urinário inferior em crianças brasileiras. A avaliação das equivalências conceitual e de itens se deu por meio de discussão com um grupo de profissionais que atuam na área de nefropediatria (médico, enfermeiro e psicólogo) do Ambulatório de Nefropediatria do Hospital Universitário Julio Mülle (HUJM) da Universidade Federal de Mato Grosso e pelas coordenadoras do projeto (uma fisioterapeuta com formação em uroginecologia e uma nutricionista).

Para que os participantes conhecessem os conceitos e definições teóricas de disfunção do trato urinário inferior na língua original, três semanas antes da reunião, forneceram-se aos membros do grupo publicações utilizadas na construção do instrumento original e procurouse identificar as mesmas questões em publicações nacionais.

Durante a discussão, utilizou-se um roteiro semi-estruturado que abordava os seguintes pontos: (1) conceitos e definições teóricas de disfunção do trato urinário inferior na criança, considerando as culturas canadense e brasileira; (2) se os conceitos mensurados por meio do instrumento original são pertinentes em nosso meio; (3) se as duas dimensões presentes no instrumento original - sintomas miccionais/ gastrointestinais e problemas social/familiar - são adequadas e suficientes para expressar o conceito de disfunção do trato urinário inferior; (4) adequação de cada item do instrumento original em relação à sua capacidade para representar tais dimensões na população onde o instrumento pretende ser utilizado. As discussões foram gravadas e transcritas e, em adição ao conhecimento acumulado durante estas, a análise do material revelou concordância das opiniões no grupo de profissionais.

Após a discussão conceitual, o instrumento original foi traduzido por dois tradutores, de forma independente, que têm o português como a língua materna ${ }^{9}$. Estes foram informados sobre a população alvo do instrumento original - crianças de 3 a 10 anos que poderiam ser auxiliadas pelos pais ou responsável -, para garantir a linguagem apropriada para esta faixa etária 7, ressaltando-se que o instrumento foi proposto como auto-aplicável. A partir da avaliação da equivalência conceitual e de itens, das duas traduções e das discussões com a equipe de investigadores, obteve-se a primeira versão em português do DVSS, finalizando a Etapa 1 (Figura 1).
Figura 1

Esquema do processo de adaptação transcultural do Dysfunctional Voiding Scoring System (DVSS).

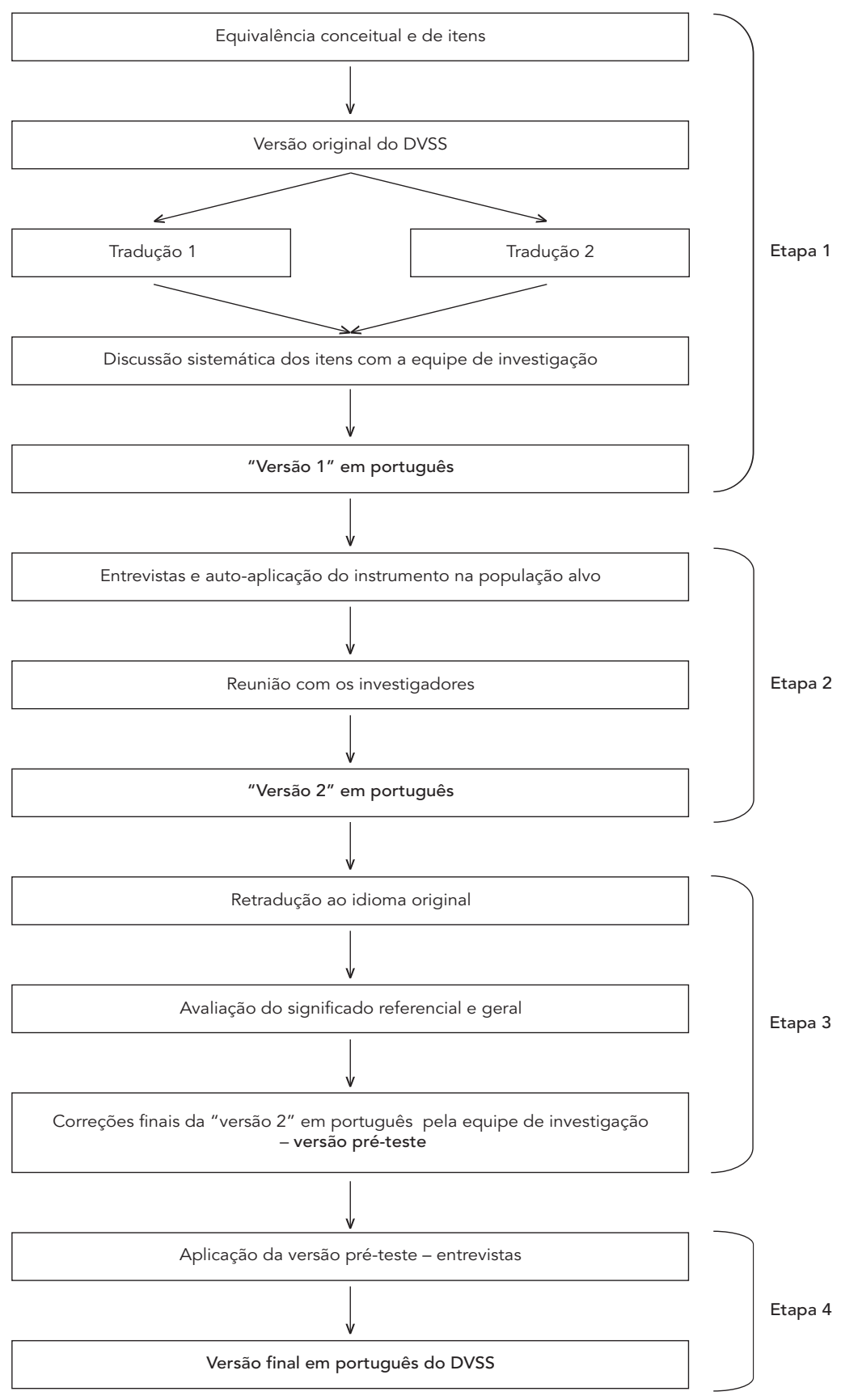

Adaptado de Serra-Sutton et al. 10. 
Etapa 2: aplicação do instrumento na população alvo

Durante o trabalho de campo observou-se que o instrumento teria um melhor desempenho se respondido pelos pais/responsáveis na presença da criança. Assim os itens na versão em português foram elaborados não na primeira pessoa do singular como no original, mas sim na terceira pessoa.

As entrevistas, ocorridas entre abril e agosto de 2007, foram realizadas com duplas (criança/ responsável) nas quais a criança demandava algum atendimento do setor de pediatria geral do Centro de Saúde Escola Grande Terceiro (CSEGT), não necessariamente apresentando alguma patologia. Outras foram realizadas com usuários do Ambulatório de Nefropediatria do HUJM, hospital público de referência para distúrbios dos tratos urinários inferior e superior. Para estes, os sintomas apresentados no instrumento são familiares, uma vez que eram portadores destes distúrbios. Foram excluídas crianças com distúrbios neurológicos que apresentavam retardo evidente no desenvolvimento neuropsicomotor e/ou mental, e crianças com diagnóstico de malformação congênita do aparelho urinário e/ou gastrointestinal.

Por meio de entrevistas semi-estruturadas 14, o entrevistador lia cada item do instrumento para a dupla respondente (criança/responsável), que o lia novamente e marcava com um "X" a resposta pertinente. As entrevistas foram gravadas e transcritas, o que permitiu observar o "nível de compreensão e naturalidade de percepção” dos itens, identificando-se dificuldades nas respostas aos itens, que doravante serão denominadas "erro" 15 . Por exemplo, quando o entrevistado respondia após um período de silêncio, o entrevistador perguntava: "Você demorou um pouco para responder, o que você estava pensando?”.

As modificações sobre o período recordatório, itens e opções de resposta foram implementadas no instrumento durante as entrevistas. Estas modificações foram denominadas de "versões" 1 a 9. As entrevistas foram realizadas pelo autor principal da pesquisa (M.R.) com o intuito de assegurar uniformidade e, por ser ligado à área de nefropediatria, verificar a adequação do vocabulário e apreciar a compreensão e relevância das perguntas.

Os comentários e alternativas propostas pelos respondentes durante as entrevistas foram avaliados pela equipe de investigação, gerando mudanças e uma segunda versão em português do DVSS, concluindo a Etapa 2 (Figura 1).
Etapa 3: retradução ao idioma original, avaliação da equivalência semântica sob a perspectiva do significado referencial e conotativo (geral) e versão pré-teste

A segunda versão em português foi retraduzida para o inglês por um tradutor de língua materna inglesa que apresentava fluência na língua portuguesa, não familiarizado com o conceito explorado no instrumento original e também não ligado à área de saúde 8 .

A avaliação semântica foi realizada segundo proposto por Reichenheim et al. ${ }^{9} \mathrm{e}$ inclui aspectos relativos ao significado referencial e geral de cada item, do período recordatório e das opções de resposta. Por meio de avaliação do significado referencial, investiga-se a correspondência literal entre os termos/palavras presentes no instrumento original e na versão traduzida. No significado geral procura-se avaliar o impacto que termos ou frases têm no contexto cultural da população alvo.

Para avaliar o significado referencial, dos termos ou palavras constituintes, compararam-se os dois instrumentos (questionário original e edição retraduzida) utilizando-se escala analógica visual (Visual Analogue Scale - VAS) 9, que permite verificar a equivalência entre as questões de forma contínua, com valores entre $0 \%$ a $100 \%$. A avaliação foi feita, com base no resultado médio a partir de pontuação dada de forma independente, por dois tradutores com formação em Letras e especialização em inglês (Departamento de Letras, Universidade Federal de Mato Grosso).

Para a avaliação do significado geral (conotativo) comparou-se a versão original, em inglês, com a traduzida para o português ("versão 2"). Utilizou-se um formulário com quatro categorias: inalterado, pouco alterado, muito alterado ou completamente alterado. A apreciação foi realizada, também de forma independente, por dois profissionais, sendo um ligado à área de saúde coletiva com especialização em inglês e outro especializado em nefropediatria 9 .

Finalizando esta etapa, a equipe de investigação apreciou as avaliações, clarificou possíveis incongruências e propôs uma versão pré-teste (Figura 1).

\section{Etapa 4: aplicação da versão pré-teste, aceitabilidade do instrumento e compreensão da versão final}

A versão pré-teste foi aplicada em dois grupos, cada um com dez duplas (crianças de 3 a 10 anos e respectivos responsáveis) do CSEGT e do Ambulatório de Nefropediatria do HUJM, no período de setembro de 2007. 
Nesta fase avaliaram-se a compreensão do vocabulário e aceitabilidade do instrumento. A equipe de investigação discutiu os comentários dos entrevistados destacando o que ainda era problema na compreensão das opções de resposta e itens, e suas possíveis alternativas para resolvê-los, sendo proposta uma versão final (Figura 1).

\section{Aspectos éticos}

O estudo foi aprovado pelo Comitê de Ética em Pesquisa do HUJM, no dia 02 de janeiro de 2007.

\section{Resultados}

Etapa 1: julgamento da equivalência conceitual e de itens e modificações após traduções - obtenção da primeira versão em português do DVSS

Os conceitos abarcados pelo instrumento original foram considerados pertinentes em nosso meio, pois também reconhecemos a disfunção do trato urinário inferior como um evento que gera alta morbidade. O grupo concordou que todos os itens são relevantes em nossa cultura e que captam, adequadamente, os domínios avaliados no instrumento original indicando existência de equivalência de itens.

As traduções foram comparadas e discutidas, sendo realizadas algumas modificações: nos dois primeiros itens, considerou-se importante acrescentar a palavra " $x i x i$ " para que ficasse bem claro o sintoma a ser avaliado (incontinência urinária). O item 2 foi estruturado com palavras presentes nas duas traduções no qual manteve-se o termo "cueca/calcinha" ao invés de "roupa de baixo", mais comum na linguagem infantil. O verbo considerado mais apropriado para este item foi " $m o$ lhar de xixi”, e não "fazer xixi”, para dar ênfase à perda urinária.

O item 3 incitou a discussão, pois na tradução literal (T1) - "eu sinto falta do meu intestino funcionando todo dia" - levaria a uma má interpretação por parte do respondente. Considerando o que se deseja avaliar nesta questão é se a criança evacua ou não todos os dias, e não se esta sente falta do ato de evacuar todos os dias, optou-se pela afirmação "eu não faço cocô todos os dias", pois segundo as tradutoras o termo "miss" em inglês significa deixar de fazer alguma coisa e, não somente, "sentir falta" de alguma coisa. Além disso, na população brasileira em geral, o termo "intestino" não é muito utilizado no dia a dia, podendo gerar dúvidas quanto ao seu significado.
No item 7, optou-se pelo termo "preciso fazer xixi" da primeira tradução ao invés de "quero fazer xixi" para elucidar a presença ou não de urgência miccional (vontade inadiável de urinar), pois nesse caso a criança não tem opção de querer ou não, ela "precisa” fazer xixi.

No item 10 foi sugerida a modificação dos termos "novo bebê, nova casa e nova escola", que é a tradução literal, para "bebê novo em casa, mudança de casa e mudança de escola”, apresentados na primeira tradução. Por exemplo, um "novo bebê" relaciona-se ao nascimento de um irmão e um "bebê novo" pode ser a presença de qualquer bebê novo, um bebê adotado, um primo etc. Em relação à nova casa e nova escola, deve-se deixar bem claro que o que poderia gerar sintomas numa criança é a mudança para outra casa ou escola, e não o fato de a casa ou a escola ser nova ou velha.

Etapa 2: modificações implementadas no instrumento durante as entrevistas com a população alvo - obtenção da segunda versão em português do DVSS

Realizaram-se 26 entrevistas no Ambulatório de Nefropediatria do HUJM e 37 no setor de Pediatria Geral do CSEGT com tempo médio de 16 minutos.

No HUJM, do total de 260 respostas (10 para cada uma das 26 entrevistas) verificaram-se 53 (20,4\%) "erros" de interpretação. No CSEGT ocorreram $73(19,7 \%)$ "erros" no total de 370 respostas (10 para cada uma das 37 entrevistas). Nos dois locais, foi observado que os itens com maiores índices de "erros" foram: item 3 $-22,2 \%$ e item $5-32,5 \%$ (Tabela 1). O restante teve percentual abaixo de $15 \%$ de "erros". Nos cinco parágrafos seguintes serão exemplificados os "erros" para cada item, e as modificações implementadas.

Na "versão 1" foram modificados os itens 5 e 7. Os entrevistados, no item 5 , ao invés de responderem em relação à freqüência miccional, respondiam em relação à evacuação, uma vez que seguiam a seqüência dos dois itens anteriores que abordavam alterações na evacuação, sendo assim, incluiu-se no item o termo "fazer xixi". No item 7, o termo "eu não consigo esperar" foi substituído por "eu não posso esperar", pois a urgência miccional, sintoma avaliado neste item, pressupõe impossibilidade de postergar a micção.

$\mathrm{Na}$ "versão 2" foram alterados os itens 6, 9 e 10. No item 6, o verbo "conseguir" foi retirado, pois, os respondentes interpretavam a questão em relação à capacidade ou não de "conseguir" segurar o xixi, porém o que estava sendo avalia- 
Número e proporção de erros em cada item no instrumento ("versão 1") aplicado no Ambulatório de Nefropediatria do Hospital Universitário Julio Mülle (HUJM) da Universidade Federal de Mato Grosso e Centro de Saúde Escola Grande Terceiro (CSEGT). Cuiabá, Mato Grosso, Brasil, 2007.

\begin{tabular}{|c|c|c|c|c|c|c|}
\hline \multirow[t]{2}{*}{ Item } & \multicolumn{2}{|c|}{ HUJM * } & \multicolumn{2}{|c|}{ CSEGT ** } & \multicolumn{2}{|c|}{ Total } \\
\hline & Erros *** & $\%$ & Erros *** & $\%$ & Erros *** & $\%$ \\
\hline 1 & 2 & 3,8 & 5 & 6,8 & 7 & 5,6 \\
\hline 2 & 4 & 7,5 & 4 & 5,5 & 8 & 6,3 \\
\hline 3 & 10 & 18,9 & 18 & 24,7 & 28 & 22,2 \\
\hline 4 & 3 & 5,7 & 1 & 1,4 & 4 & 3,2 \\
\hline 5 & 17 & 32,1 & 24 & 32,9 & 41 & 32,5 \\
\hline 6 & 5 & 9,4 & 6 & 8,2 & 11 & 8,7 \\
\hline 7 & 6 & 11,3 & 9 & 12,3 & 15 & 11,9 \\
\hline 8 & 0 & 0,0 & 3 & 4,1 & 3 & 2,4 \\
\hline 9 & 3 & 5,7 & 0 & 0,0 & 3 & 2,4 \\
\hline 10 & 3 & 5,7 & 3 & 4,1 & 6 & 4,8 \\
\hline Total & 53 & 100,0 & 73 & 100,0 & 126 & 100,0 \\
\hline
\end{tabular}

* Total de 260 respostas;

** Total de 370 respostas;

$\star \star \star$ Total de erros no universo de respostas.

do era a realização ou não de manobras de contenção para evitar a perda urinária. Substituiuse também o termo "dança do xixi" para apenas "dançando", pois o primeiro gerava surpresa e constrangimento nos respondentes do CSEGT com posterior negativa, a criança logo dizia: "eu não faço isto". No item 9 foi incluído entre parênteses, "em relação aos últimos 30 dias", pois os entrevistados respondiam em relação a dores ocorridas em qualquer período. $\mathrm{O}$ mesmo se deu no item 10, no qual as respostas muitas vezes correspondiam a eventos estressantes ocorridos há mais de um mês. Isto era detectado ao perguntar ao respondente a data de ocorrência do evento.

Da “versão 3" até a "versão 9", os itens 3 e 5 foram modificados conforme a dificuldade de interpretação. No item 3 o entrevistado não respondia em relação ao que estava escrito e sim ao que acontecia com ele, ou seja, a pergunta provocava a resposta inversa: "Eu não faço cocô todos os dias"; quando a criança evacuava todos os dias, a mãe dizia: "elelela faz todos os dias", então marcava "quase o tempo todo" ao invés de "quase nunca". Também no item 5 os respondentes invertiam a resposta, quando se lia "eu só vou ao banheiro urinar uma ou duas vezes por dia", falavam que iam mais vezes e marcavam "quase o tempo todo" ao invés de "quase nunca”.
Nos itens 3 e 5 da última versão foi acrescentada uma assertiva possibilitando ao entrevistado dar continuidade entre o item e a opção de resposta, e assim evitar as inversões na resposta. No item 3, na expressão - "Eu não faço cocô todos os dias" - acrescentou-se "Este problema de não fazer cocô geralmente acontece:”. No caso de o respondente evacuar todos os dias, responderia "quase nunca" e se este não evacuasse todos os dias, conforme a frequência teria que escolher entre as outras três opções - "menos que a metade do tempo", "mais ou menos a metade do tempo" ou "quase o tempo todo". No item 5 - "Eu só vou ao banheiro fazer xixi uma ou duas vezes por dia" - acrescentou-se "Este problema de urinar poucas vezes por dia geralmente acontece:". Se o entrevistado urinasse uma ou duas vezes por dia, responderia "quase o tempo todo" e se urinasse com freqüência normal, ou seja, mais de três vezes por dia, marcaria "quase nunca".

Na “versão 5” não houve alterações nos itens, porém nas opções de resposta, "quase o tempo todo" foi substituído por "quase diariamente", não mostrando resultados efetivos. O período recordatório passou de "durante o último mês" para "durante os últimos 30 dias", pois a expressão "último mês" poderia referir-se ao mês anterior, e não aos últimos 30 dias. 
Etapa 3: avaliação da equivalência semântica sob a perspectiva do significado referencial e geral - obtenção da versão pré-teste

$\mathrm{Na}$ avaliação da equivalência semântica sob a perspectiva do significado referencial entre o instrumento original e o retraduzido, o primeiro avaliador colocou $80 \%$ dos itens com concordância completa (100\%), e os 20\% restantes, en- tre $80 \%$ e $90 \%$ (Tabela 2). O avaliador justificou sua posição em relação ao período recordatório (80\%) - "over the last month" I"during the last 30 days" - dizendo que a expressão "último mês", presente no instrumento original, poderia referir-se ao mês anterior, e não aos últimos 30 dias. A equipe de investigação fez a opção "durante os últimos 30 dias" por perceber que nas entrevistas ocorreram muitas dúvidas em relação ao período

Tabela 2

Equivalência semântica sob a perspectiva do significado referencial entre o instrumento original e o retraduzido.

\begin{tabular}{|c|c|c|c|c|}
\hline Original & Retraduzido & $\begin{array}{l}\text { Avaliador } 1 \\
\text { Concordância } \\
\text { (\%) }\end{array}$ & $\begin{array}{l}\text { Avaliador } 2 \\
\text { Concordância } \\
\text { (\%) }\end{array}$ & $\begin{array}{l}\text { Síntese } \\
\text { Concordância } \\
\text { (\%) }\end{array}$ \\
\hline Over the last month & During the last 30 days & 80,0 & 100,0 & 90,0 \\
\hline $\begin{array}{l}\text { 1. I have had wet clothes or wet underwear } \\
\text { during the day. }\end{array}$ & 1. I have wet my clothes with pee during the day. & 100,0 & 80,0 & 90,0 \\
\hline $\begin{array}{l}\text { 2. When I wet myself, my underwear is } \\
\text { soaked. }\end{array}$ & $\begin{array}{l}\text { 2. When I wet myself with pee } \\
\text { my underpants get soaked. }\end{array}$ & 100,0 & 80,0 & 90 \\
\hline $\begin{array}{l}\text { 3. I miss having a bowel movement } \\
\text { every day. }\end{array}$ & $\begin{array}{l}\text { 3. I don't have a poop every day. } \\
\text { This problem of not having a poop normally happens: }\end{array}$ & 100,0 & 90,0 & 95,0 \\
\hline $\begin{array}{l}\text { 4. I have to push for my bowel } \\
\text { movements to come out. }\end{array}$ & 4. I have to push to do a poop. & 100,0 & 100,0 & 100,0 \\
\hline $\begin{array}{l}\text { 5. I only go to the bathroom one or } \\
\text { two times each day. }\end{array}$ & $\begin{array}{l}\text { 5. I only go to the toilet to pee once or twice a day. } \\
\text { This problem of having a pee just a few } \\
\text { times a day normally happens: }\end{array}$ & 100,0 & 90,0 & 95,0 \\
\hline $\begin{array}{l}\text { 6. I can hold onto my pee by crossing my } \\
\text { legs, squatting or doing the "pee dance". }\end{array}$ & $\begin{array}{l}\text { 6. I hold back my pee by crossing my legs, } \\
\text { crouching or dancing. }\end{array}$ & 90,0 & 100,0 & 95,0 \\
\hline 7. When I have to pee, I cannot wait. & 7. When I need to pee I can't wait. & 100,0 & 100,0 & 100,0 \\
\hline 8. I have to push to pee. & 8. I have to try hard to pee. & 100,0 & 100,0 & 100,0 \\
\hline 9. When I pee it hurts. & 9. When I pee it hurts (in the last 30 days). & 100,0 & 100,0 & 100,0 \\
\hline $\begin{array}{l}\text { 10. Parents to answer. Has your child } \\
\text { experienced something stressful like } \\
\text { the example below? }\end{array}$ & $\begin{array}{l}\text { 10. For parents to reply: Has your son/daughter been } \\
\text { through any kind of stressful situation such as the examples } \\
\text { below in the last } 30 \text { days? Tick yes or no next to each one. }\end{array}$ & & & \\
\hline - New baby & - A new born baby at home & & & \\
\hline - New home & - Change of house & & & \\
\hline - New school & - Change of school & & & \\
\hline - School problems & - School problems & & & \\
\hline - Abuse (sexual/physical) & - Abuse (sexual/physical) & & & \\
\hline - Home problems (divorce/death) & - Problem at home (divorce/death) & & & \\
\hline - Special events (birthday) & - Special events (birthday) & & & \\
\hline - Accident/Injury & - Accident/Injury & & & \\
\hline - Others & - Others & & & \\
\hline Almost never & Almost never & 100,0 & 100,0 & 100,0 \\
\hline Less than half the time & Less than half the time & 100,0 & 100,0 & 100,0 \\
\hline About half the time & More or less half the time & 100,0 & 100,0 & 100,0 \\
\hline Almost every time & Almost always & 80,0 & 100,0 & 90,0 \\
\hline Concordância total & & 96,6 & 96,0 & 96,3 \\
\hline
\end{tabular}

Nota: trechos sublinhados correspondem aos trechos da versão retraduzida onde ocorreram as alterações mais significativas em relação ao instrumento original. 
recordatório, sendo este o período a que o instrumento alude.

Em relação à opção de resposta “almost always", a equivalência foi avaliada em $80 \%$. O avaliador opinou que "almost every time" [quase toda vez], utilizado no instrumento original, é referente ao número de vezes que se faz algo. Já "almost always" significa [quase todo o tempo ou quase sempre] e refere-se ao tempo contado em minutos, dias, semanas etc. A tradução literal para o português desta opção de resposta - "quase toda vez" - não é apropriada para os itens 3 e 5, sendo assim, manteve-se o termo traduzido na primeira versão - "quase todo o tempo".

$\mathrm{Na}$ avaliação do significado referencial feita pelo segundo avaliador, $73 \%$ dos itens apresentaram concordância completa (100\%) e os $27 \%$ restantes, entre $80 \%$ e $90 \%$. Nos itens 1 e 2 , foi colocado que os pesquisadores que desenvolveram o instrumento original não utilizaram a palavra "xixi", apenas colocaram "eu tenho molhado a minha roupa durante o dia" e "quando me molho, minhas roupas de baixo ficam ensopadas". A equipe de investigação optou por utilizar a segunda tradução que incluía a palavra "xixi" nos itens 1 e 2, visto que os dois itens eram referentes à perda urinária.

$\mathrm{Na}$ avaliação do significado geral a grande maioria dos itens foi considerada "inalterada" ou "pouco alterada" pelos aferidores, apenas o item 5 foi avaliado como "muito alterado" e nenhum item como "completamente alterado".

Com base nas avaliações semânticas alguns itens demandaram pequenos ajustes para a versão pré-teste a ser utilizada na quarta etapa. Após discussão e consenso entre os membros da equipe de investigação, a segunda versão utilizou a pergunta na terceira pessoa para facilitar o processo de aferição baseado em entrevistas, forma mais apropriada para nossa realidade. Nos ajustes finais decidiu-se que na opção de resposta "quase nunca" deveria-se utilizar "nunca ou quase nunca", pois muitos pais ficavam na dúvida sobre o que responder quando a criança não tinha o sintoma. No item 7 - "Quando eu preciso fazer xixi, eu não posso esperar" - foi incluída uma segunda expressão para fortalecer o que está sendo avaliado neste item: "Quando seu(a) filho(a) precisa fazer xixi, não pode esperar, tem que ir rápido ao banheiro?", pois muito da dificuldade deste item estava no fato de que o entrevistado respondia em relação à capacidade de segurar a urina e não avaliava a urgência miccional, sintoma presente em crianças com disfunção do trato urinário inferior.
Etapa 4: aplicação da versão pré-teste obtenção da versão final

A versão pré-teste foi aplicada em vinte duplas (criança/responsável) nos mesmos serviços de saúde. A grande maioria das modificações foi bem aceita, sendo observado que os itens 3 e 5 apresentaram maiores índices de "erro" (3/20 e $6 / 20$, respectivamente). A equipe discutiu as respostas dos entrevistados e, em virtude de todas as alterações possíveis nesses dois itens terem sido efetuadas, decidiu-se que essa seria a versão final do DVSS (Figura 2). Ressalta-se que o instrumento deve ser aplicado por entrevistador treinado e nesses dois itens deve-se tomar cuidado, pois pode ocorrer inversão de resposta.

A aceitabilidade do instrumento foi excelente, nenhum respondente se recusou a terminar a entrevista. O tempo médio das entrevistas, inicialmente de 16 minutos (média de tempo das primeiras vinte entrevistas realizadas na Etapa 2), baixou para 9 minutos (média de tempo das vinte entrevistas realizadas na Etapa 4).

Na Tabela 3 estão expostas todas as versões em português do DVSS - versões 1 e 2, versão pré-teste e versão final.

\section{Discussão}

O estudo apresenta uma versão do instrumento validado e proposto originalmente em inglês, adaptado para a cultura brasileira seguindo um modelo de equivalência transcultural proposto por Herdman et al. 7 e adaptado por Reichenheim \& Moraes 16.

No Brasil existem poucas investigações epidemiológicas na área de disfunção do trato urinário inferior e por meio de revisão de literatura, não foi identificado instrumento brasileiro validado que avalie os sintomas miccionais em crianças. Tendo em vista a dificuldade de abordagem dos pacientes com suspeita de desordens funcionais do trato urinário, instrumentos de aferição foram desenvolvidos com intuito de detectar potenciais portadores destas. Entretanto os instrumentos existentes para detectar disfunção do trato urinário inferior foram desenvolvidos em países de língua inglesa, muitas vezes sendo traduzidos do original para a língua alvo pelos próprios pesquisadores, o que pode comprometer a qualidade das informações dos resultados obtidos.

A necessidade da adaptação transcultural é apresentada por diversos autores 17,18,19 e os dilemas e dificuldades surgidos ao longo do processo de adaptação do DVSS reforçam o quanto é imprescindível a avaliação meticulosa da 
Versão final do Dysfunctional Voiding Scoring System (DVSS) em português.

Prezada Mãe ou Responsável,

As questões descritas abaixo são para conhecermos os problemas relacionados à micção (urinar = fazer "xixi") e à evacuação (fazer "cocô").

Por favor, marque com um X a opção que tenha acontecido com seu(a) filho(a) nos últimos 30 dias

Sistema de avaliação da disfunção do trato urinário inferior *

Nome:

Instituição:

Data de nascimento: ___ _ _ _ _ _ _ _ _ _ _ _ _ _ _

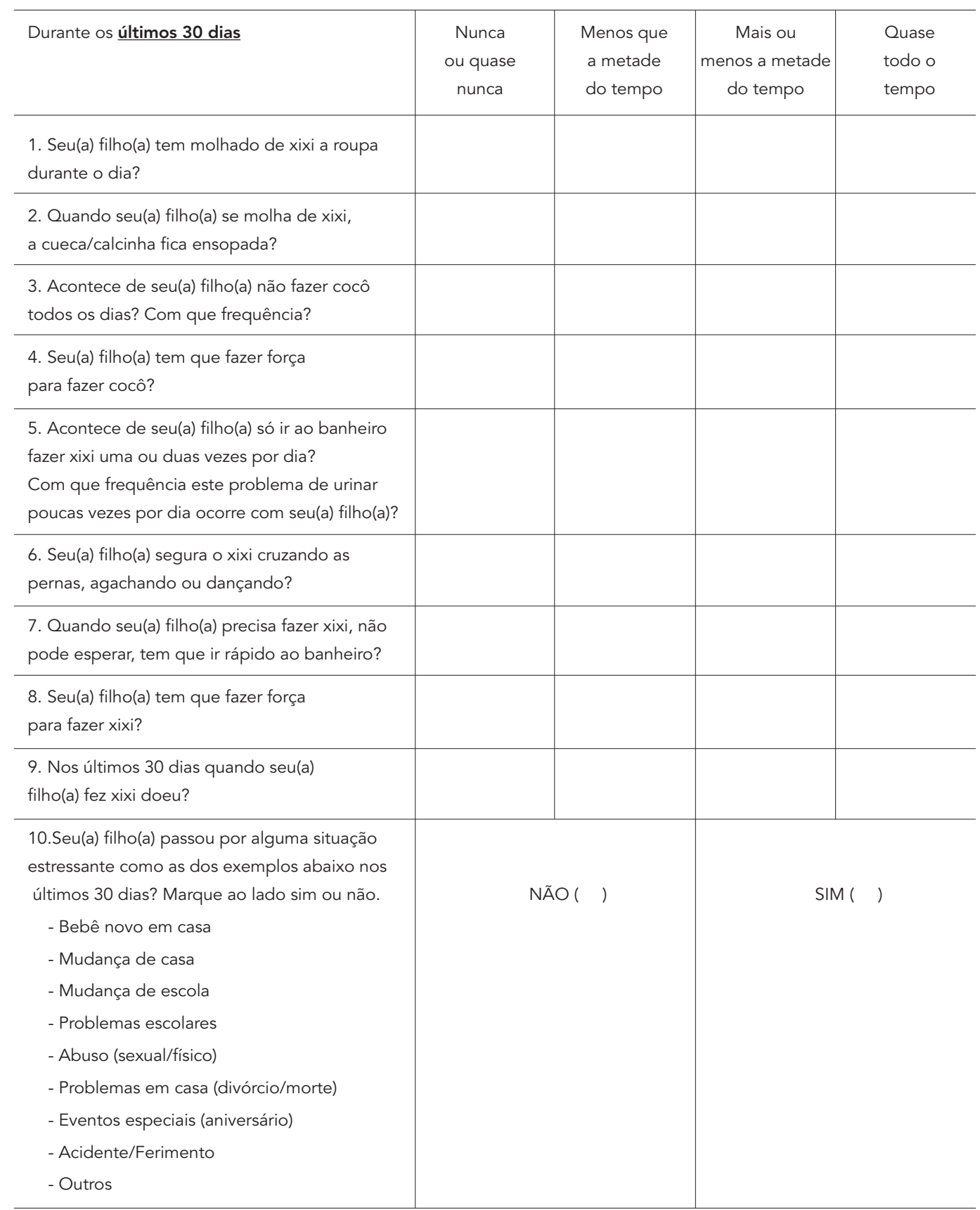

* Adaptado culturalmente de Farhat et al. 5. 
Desenvolvimento das versões em português do Dysfunctional Voiding Scoring System (DVSS).

\begin{tabular}{lll}
\hline "Versão 1" em português após & "Versão 2" em português após & Versão pré-teste = versão final \\
as duas traduções & entrevistas com a população alvo & (Etapas 3 e 4) \\
(Etapa 1) & (Etapa 2) &
\end{tabular}

Durante o último mês

1. Eu tenho molhado de xixi a minha roupa durante o dia.

2. Quando me molho de xixi, minha cueca/calcinha fica ensopada.

3. Eu não faço cocô todos os dias. de não fazer cocô geralmente acontece:

4. Eu tenho que fazer força para fazer cocô.

5. Eu só vou ao banheiro uma ou duas vezes por dia.

poucas vezes por dia geralmente acontece:

6. Eu consigo segurar o xixi cruzando minhas pernas, agachando ou fazendo

a "dança do xixi".

7. Quando eu preciso fazer xixi, eu não consigo esperar.

8. Eu tenho que fazer força para fazer xixi.

9. Quando eu faço xixi dói.

10. Para os pais responderem:

Seu(a) filho(a) passou por alguma situação

estressante como as dos exemplos abaixo?

- Bebê novo em casa

- Mudança de casa

- Mudança de escola

- Problemas escolares

- Abuso (sexual/físico)

- Problemas em casa (divórcio/morte)

- Eventos especiais (aniversário)

- Acidente/Ferimento

- Outros

\section{Quase nunca}

Menos que a metade do tempo

Mais ou menos a metade do tempo

Quase todo o tempo
Durante os últimos 30 dias

1. Eu tenho molhado de xixi a minha

roupa durante o dia.

2. Quando me molho de xixi, minha cueca/calcinha fica ensopada.

3. Eu não faço cocô todos os dias. Este problema cocô todos os dias? Com que frequência?

4. Eu tenho que fazer força para fazer cocô.

5. Eu só vou ao banheiro fazer xixi uma ou duas vezes por dia. Este problema de urinar frequência este problema de urinar poucas vezes por dia ocorre com seu(a) filho(a)?

6. Eu seguro o xixi cruzando minhas pernas, agachando ou dançando.

7. Quando eu preciso fazer xixi, eu não posso esperar.

8. Eu tenho que fazer força para fazer xixi.

9. Quando eu faço xixi dói (nos últimos 30 dias). fez xixi doeu?

10. Para os pais responderem: Seu(a) filho(a) passou por alguma situação estressante como as dos exemplos abaixo nos últimos 30 dias? Marque ao lado sim ou não.

- Bebê novo em casa

- Mudança de casa

- Mudança de escola

- Problemas escolares

- Abuso (sexual/físico)

- Problemas em casa (divórcio/morte)

- Eventos especiais (aniversário)

- Acidente/Ferimento

- Outros

Quase nunca

Menos que a metade do tempo

Mais ou menos a metade do tempo

Quase todo o tempo
Durante os últimos 30 dias

1. Seu(a) filho(a) tem molhado de xixi a

roupa durante o dia?

2. Quando seu(a) filho(a) se molha de xixi,

a cueca/calcinha fica ensopada?

3. Acontece de seu(a) filho(a) não fazer

4. Seu(a) filho(a) tem que fazer força para fazer cocô?

5. Acontece de seu(a) filho(a) só ir ao banheiro fazer xixi uma ou duas vezes por dia? Com que

6. Seu(a) filho(a) segura o xixi cruzando as pernas, agachando ou dançando?

7. Quando seu(a) filho(a) precisa fazer xixi, não pode esperar, tem que ir rápido ao banheiro?

8. Seu(a) filho(a) tem que fazer força para fazer xixi?

9. Nos últimos 30 dias quando seu(a) filho(a)

10. Seu(a) filho(a) passou por alguma situação estressante como as dos exemplos abaixo nos últimos 30 dias? Marque ao lado sim ou não.

- Bebê novo em casa

- Mudança de casa

- Mudança de escola

- Problemas escolares

- Abuso (sexual/físico)

- Problemas em casa (divórcio/morte)

- Eventos especiais (aniversário)

- Acidente/Ferimento

- Outros

Nunca ou quase nunca

Menos que a metade do tempo

Mais ou menos a metade do tempo

Quase todo o tempo equivalência entre o instrumento original e sua versão traduzida.

O primeiro recurso sugerido por Herdman et al. 7 para se alcançar a equivalência conceitual refere-se à consulta bibliográfica do tema em ambas culturas. Esta primeira abordagem foi essencial para que a discussão do grupo de profissionais pudesse ir além das práticas diárias de cada um, estudando e atualizando conceitos e definições da disfunção do trato urinário inferior por meio de publicações na cultura de origem do instrumento e na cultura alvo. 
A discussão com profissionais que participaram da avaliação da equivalência conceitual e de itens foi facilitada por estes serem especializados e atuantes em nefropediatria. A experiência destes profissionais com crianças portadoras de disfunção do trato urinário inferior possibilitou conhecer intimamente suas queixas e problemas, inclusive suas falas e sentimentos. Este fator contribuiu para amenizar uma limitação do estudo, que foi a não participação de membros da população na discussão conceitual, que investigaria seus conhecimentos em relação aos sintomas e questões sócio-familiares presentes nos distúrbios funcionais do trato urinário inferior.

A colaboração dos tradutores foi essencial na primeira etapa do processo principalmente na construção da "versão 1", pois esclareceram os possíveis usos das palavras e termos que poderiam ser utilizados sem alterar o contexto, além de apontar os limites da língua inglesa, sua adaptabilidade e correspondência para o português. Esta etapa foi essencial para constatarmos que o DVSS é um instrumento passível de ser utilizado na população brasileira e também para conhecêlo detalhadamente, com suas dificuldades iniciais de adaptabilidade cultural.

As gravações e posteriores transcrições, nas Etapas 1 e 2 foram essenciais. Nas entrevistas, algumas vezes, o correto entendimento das respostas só foi alcançado após várias audições da fala dos respondentes. As gravações também foram importantes para melhorar o desempenho do entrevistador, no que diz respeito à condução da entrevista, resolução de dúvidas e elaboração de perguntas.

Na Etapa 2 da pesquisa, os itens, opções de resposta e período recordatório com problemas de compreensão exigiram diversos ajustes e testes. Segundo Streiner \& Norman 19 são realizadas quantas entrevistas forem necessárias até que pouca ou nenhuma nova informação seja acrescida, e isto se dá, na maioria dos casos, entre 8 e 15 entrevistas qualitativas. No entanto, foram necessárias 63 entrevistas para se chegar à "versão 2" do instrumento em português. Sendo assim, esta etapa foi identificada pela equipe de investigação como de máxima importância neste processo de adaptação transcultural do DVSS, permitindo assim uma posterior avaliação semântica, feita com uma versão já trabalhada e modificada, mais próxima da versão final.

Por meio das entrevistas observou-se que as modificações feitas durante a Etapa 1 para obtenção da "versão 1", foram bem aceitas. Verificouse que os itens que apresentaram problemas na primeira fase não corresponderam inteiramente aos problemas da Etapa 2. Inicialmente apenas os itens 1, 2, 3 e 4 foram considerados proble- máticos, depois se verificaram também por meio das entrevistas, erros e dificuldades na compreensão dos itens 5, 6, 7 e 10.

As inversões de resposta dos itens 3 e 5 só foram descobertas por meio das entrevistas, sendo necessárias diversas modificações para se resolver o problema. A equipe de investigação debateu sobre a fala dos entrevistados, que disseram que os itens 3 e 5 deveriam ter opções de resposta dicotômica sim/não. Também foi debatida a possibilidade de inverter os itens 3 e 5 , pois no instrumento original estes avaliam sintomas (p. ex.: "eu não faço cocô todos os dias"), entretanto na versão em português "eu faço cocô todos os dias", refere-se a um padrão de normalidade. Esta alternativa foi posteriormente descartada pela equipe de investigação, uma vez que os escores ficariam invertidos ("quase nunca" passaria a valer 3 pontos e "quase todo o tempo" valeria 0 pontos), gerando confusão no somatório dos pontos. Com a incorporação de 2 perguntas, os itens 3 e 5 foram melhor compreendidos pelos entrevistados, desde que a aplicação do DVSS seja realizada por entrevistas, levando em consideração a possibilidade de inversão das respostas por parte dos respondentes, principalmente em populações com baixo nível de escolaridade. Neste caso, o entrevistador deve chamar a atenção do respondente para o que está sendo avaliado e não ao que normalmente acontece com a criança. Na versão final, portanto, o escore máximo e mínimo se mantiveram idênticos em relação à versão original.

A opção por conduzir a retradução somente após as entrevistas mostrou-se de fundamental importância para a qualidade do instrumento adaptado. Muitos estudos 9,10,18 realizam esta etapa logo após as traduções iniciais para a língua alvo, gerando retraduções muito semelhantes ao instrumento original, uma vez que vários termos corretos do ponto de vista literal podem não ser os utilizados pela população alvo. As avaliações dos significados referencial e geral indicaram existência de qualidade no instrumento adaptado.

De modo geral, os resultados da avaliação semântica mostraram que não houve problemas de significado após as modificações efetuadas. $\mathrm{Na}$ avaliação do significado geral, o item 5 foi considerado como "muito alterado" uma vez que no instrumento original não aparecia o evento "fazer xixi", sendo assim, o item poderia estar incluindo também a evacuação. A equipe de investigação considerou pertinente o argumento do avaliador, porém a expressão "fazer xixi" foi acrescentada após as entrevistas indicarem que grande parte dos entrevistados respondia em relação à evacuação, possivelmente porque os dois 
itens anteriores (3 e 4) referem-se à evacuação. Merece observar que a avaliação do especialista deteve-se na literalidade das palavras (significado referencial) e não no impacto que uma determinada palavra/expressão causou na população alvo (significado geral), avaliação solicitada ao profissional. Nesta etapa foi detectado que o significado geral foi trabalhado naturalmente durante as entrevistas com a população alvo, simplificando o processo de avaliação da equivalência semântica. Um exemplo foi a indignação da expressão "dança do xixi" por parte das crianças nas primeiras entrevistas, esta foi modificada para o termo "dançando", sendo bem aceito.

Com um percentual médio de concordância referencial entre os avaliadores de 93,6\%, partiu-se para a versão pré-teste, onde ainda foram feitos alguns ajustes. A decisão de adaptar a versão pré-teste para a terceira pessoa se baseou na baixa escolaridade de grande parte da população brasileira 20 facilitando assim o processo de aferição, por meio de entrevistas, forma sugerida para aplicação do DVSS no Brasil.

Na Etapa 4 não houve necessidade de um grande número de entrevistas, uma vez que a grande maioria das modificações tinha sido re-

\section{Resumo}

Investiga-se a equivalência conceitual, de itens e semântica entre o instrumento Dysfunctional Voiding Scoring System (DVSS), utilizado para avaliar a disfunção funcional do trato urinário inferior em crianças, concebido em inglês e uma versão em português. Na primeira etapa realizou-se a avaliação da equivalência conceitual e de itens, seguida de duas traduções do instrumento original para o português. Na segunda etapa foram realizadas 63 entrevistas, com crianças de 3 a 10 anos e responsáveis, e modificação de itens segundo dificuldades de interpretação. Na terceira etapa foi realizada a retradução do instrumento em português para o inglês e avaliação da equivalência semântica. Na quarta etapa, a versão pré-teste foi aplicada em vinte duplas de crianças de 3 a 10 anos e responsáveis. Apresenta-se o instrumento em português com equivalência conceitual, de itens e semântica. Sugerese que a aplicação do DVSS seja realizada por meio de entrevista por profissional treinado e não baseada em autopreenchimento como proposto no instrumento original.

Transtornos Urinários; Questionários; Saúde da Criança alizada na segunda etapa. O tempo médio das entrevistas diminuiu consideravelmente (de 16 para 9 minutos), tornando-se apropriado para aplicação em ambulatório, ou mesmo incluindo em questionários de investigação de saúde da criança.

O método utilizado neste estudo mostrou-se eficaz por considerar diferentes tipos de equivalência do processo de adaptação transcultural do DVSS. Um usuário deste instrumento adaptado deve estar atento ao uso da versão em português, pois os resultados devem ser revistos após estudo da equivalência de mensuração, que consiste em comparar as propriedades psicométricas (confiabilidade e validade) do instrumento original com os da nova versão, que completará o processo de validação.

Apresenta-se o instrumento em português com a característica de equivalência conceitual, de itens e semântica. Devido às diversas dificuldades de interpretação que ocorreram durante as entrevistas, sugere-se que a coleta de informações através do DVSS seja realizada por meio de entrevista por profissional treinado e não baseada em autopreenchimento como proposto no instrumento original.

\section{Colaboradores}

M. Rizzini participou da escolha do tema, procura e revisão das publicações, organização do trabalho, revisão dos instrumentos, organização e participação nos grupos de discussão, realização das entrevistas, no préteste, montagem de figura e tabelas, discussão e edição final do artigo. G. S. Brunken contribuiu na escolha do tema, organização do trabalho, organização e participação nos grupos de discussão, montagem de figura e tabelas, discussão e edição final do artigo. T. L. Donatti colaborou na organização e participação nos grupos de discussão, discussão e edição final do artigo. D. P. Bergamaschi participou da montagem de figura e tabelas, discussão e edição final do artigo.

\section{Agradecimentos}

Os autores agradecem aos profissionais do Ambulatório de Nefropediatria do Hospital Universitário Júlio Müller, Universidade Federal de Mato Grosso: Rosa Lucia R. Ribeiro e M. Aparecida A. Fernandes, pela participação e cooperação na primeira etapa. Agradecemos aos tradutores e avaliadores: Michella Velasquez, Terezinha Márquez Nunes, Terence P. Matfield, Ian S. Dunwoodie, Johnny L. C. Hall, Esther M. Trew, Elaine T. Pereira, Lílian M. G. Salles e Ana Beatriz de F. Rabel, pela participação nas primeira e terceira etapas. Agradecimento especial a Gilberto P. P. Franco, pelas valiosas sugestões em todas as etapas. A Coordenação de Aperfeiçoamento de Pessoal de Nível Superior (CAPES) pela bolsa de mestrado concedida. 


\section{Referências}

1. Hellerstein S, Linebarger JS. Voiding dysfunction in pediatric patients. Clin Pediatr (Phila) 2003 42:43-9.

2. Fonseca EM, Monteiro LM. Diagnóstico clínico de disfunção miccional em crianças e adolescentes enuréticos. J Pediatr (Rio J.) 2004; 80:147-53.

3. Sureshkumar P, Cumming RG, Craig JC. Validity and reliability of parental report of frequency, severity and risk factors of urinary tract infection and urinary incontinence in children. J Urol 2006; 175:2254-62.

4. Kajiwara M, Inoue K, Usui A, Kurihara M, Usui T. The micturition habits and prevalence of daytime urinary incontinence in Japanese primary school children. J Urol 2004; 171:403-7.

5. Farhat W, Bagli DJ, Capolicchio G, O'Reilly S, Merguerian PA, Khoury AE, et al. The dysfunctional voiding scoring system: quantitative standardization of dysfunctional voiding symptoms in children. J Urol 2000; 164:1011-5.

6. Mota DM, Victora CG, Hallal PC. Investigação de disfunção miccional em uma amostra populacional de crianças de 3 a 9 anos. J Pediatr (Rio J.) 2005; 81:225-32.

7. Herdman M, Fox-Rushby J, Badia X. A model of equivalence in the cultural adaptation of HRQoL instruments: the universalist approach. Qual Life Res 1998; 7:323-35.

8. Beaton DE, Bombardier C, Guillemin F, Ferraz MB. Guidelines for the process of cross-cultural adaptation of self-report measures. Spine 2000; 25:3186-91.

9. Reichenheim ME, Moraes CL, Hasselmann MA. Equivalência semântica da versão em português do instrumento Abuse Assessment Screen para rastrear a violência contra a mulher grávida. Rev Saúde Pública 2000; 34:610-6.

10. Serra-Sutton V, Herdman M, Rajmil L, Santed R, Ferrer M, Siméoni MC, et al. Adaptación al español del cuestionario Vecú et Sante Perçue de L'adolescent (VSP-A): una medida genérica de calidad de vida para adolescentes. Rev Esp Salud Pública 2002; 76:701-12.

11. Reichenheim ME, Moraes CL. Adaptação transcultural do instrumento Parent-Child Conflict Tactics Scales (CTSPC) utilizado para identificar a violência contra a criança. Cad Saúde Pública 2003; 19:1701-12.
12. Duel BP, Steinberg-Epstein R, Hill M, Lerner M. A survey of voiding dysfunction in children with attention deficit-hyperactivity disorder. J Urol 2003; 170:1521-4.

13. Bartkowski DP, Doubrava RG. Ability of a normal dysfunctional voiding score to predict uroflowmetry and external urinary sphincter electromyography patterns in children. J Urol 2004; 172:1980-5.

14. Hasselmann MH, Reichenheim ME. Adaptação transcultural da versão em português da Conflict Tactics Scales Form R (CTS-1), usada para aferir violência no casal: equivalências semântica e de mensuração. Cad Saúde Pública 2003; 19:1083-93.

15. Conrad F, Blair J, Tracy E. Verbal reports are data! A theoretical approach to cognitive interviews. http://www.fcsm.gov/99papers/conrad1.pdf (acessado em 01/Dez/2006).

16. Reichenheim ME, Moraes CL. Buscando a qualidade das informações em pesquisas epidemiológicas. In: Minayo MCS, Deslandes SE, organizadores. Caminhos do pensamento: epistemologia e método. Rio de Janeiro: Editora Fiocruz; 2002. p. 227-54.

17. Guillemin F, Bombardier C, Beaton D. Cross-cultural adaptation of health-related quality of life measures: literature review and proposed guidelines. J Clin Epidemiol 1993; 46:1417-32.

18. Aires MT, Werneck GL. Tradução e adaptação cultural para o português do instrumento "The Bowel Disease Questionnaire", utilizado para a avaliação de doenças gastrointestinais funcionais. Arq Gastroenterol 2006; 43:138-53.

19. Streiner DL, Norman GR. Health measurement scales: a practical guide to their development and use. $3^{\text {rd }}$ Ed. Oxford: Oxford University Press; 2003.

20. Moraes CL, Hasselmann MA, Reichenheim ME. Adaptação transcultural para o português do instrumento "Revised Conflict Tactics Scales (CTS2)" utilizado para identificar violência entre casais. Cad Saúde Pública 2002; 18:163-76.

Recebido em 30/Jul/2008

Versão final reapresentada em 04/Fev/2009

Aprovado em 06/Abr/2009 